\title{
MAPEANDO A TI VERDE EM EMPRESAS DE CIDADES DA FRONTEIRA COM O URUGUAI
}

Joseni Cristiane de Oliveira Barboza Magalhães ${ }^{1}$

Franco Vieira Sampaio ${ }^{2}$

Resumo: Este artigo apresenta o resultado de pesquisa sobre a Tecnologia da Informação (TI) Verde em empresas de Sant'Ana do Livramento e Quaraí, localizadas no Rio Grande do Sul que fazem fronteira com o Uruguai, tendo por objetivo coletar dados relativos aos setores privados de $\mathrm{Tl}$ e investigar informações a respeito das ações de TI verde realizada e pensada pelas organizações envolvidas. Tem caráter exploratório, descritivo e indutivo, foi desenvolvida em forma de uma pesquisa de campo que propiciou melhor forma de entendimento sobre a TI Verde nas instituições privadas. O levantamento dos dados foi realizado através de questionário aplicado aos proprietários ou setor de TI das empresas.

Palavras-chave: TI Verde; Resíduos Tecnológicos; Empresas; Sustentabilidade; Cidades Fronteiriças. 


\section{Introdução}

Empresas que adotarem práticas ecologicamente corretas serão mais bem vistas no mercado em nível de reconhecimento. A atração será maior para os clientes, tanto na compra de equipamentos que levará um consumo menor, quanto em vista da sociedade, pois há uma grande preocupação com o meio ambiente e seus fenômenos (ABREU et al., 2012).

A inovação pode ser entendida como fazer "diferente" com o valor agregado, sem necessariamente ser novo. É diferente de invenção (coisa nova, criada ou concebida), que envolva a formulação de uma proposta inédita. Nesse sentido, a organização inovadora é a que oferece produtos ou presta serviços com valores agregados. A Inovação pode se dar em um produto ou serviço, em um ou mais processos, em aspectos arquitetônicos ou estéticos da organização e até mesmo no modelo de gestão da organização (REZENDE, 2008a).

A computação verde vem ganhando cada vez mais espaço, pois está voltada aos recursos tecnológicos, seu impacto no meio ambiente é uma preocupação hoje nas organizações, sendo que as constantes modificações, alterações e atualizações, geram assim inúmeros resíduos que devem receber um tratamento adequado quando feito seu descarte (NANNI; PASSOS, 2014).

Com a tecnologia tornando-se obsoleta rapidamente e, por sua vez, gerando um grande volume de lixo eletrônico e/ou e-lixo, há a necessidade de uma pesquisa que traga esclarecimentos, coerência sobre as relações entre $\mathrm{TI}$ e sustentabilidade. Desta forma, tornam-se urgentes e necessárias ações que sejam relevantes no sentido de reduzir resíduos tecnológicos e promover o descarte correto dos mesmos, preocupando-se com os aspectos ambientais.

O presente estudo visa esclarecer e orientar a comunidade empresarial nas cidades estudadas, em relação às certificações para Tecnologia da Informação - TI Verde, selo verde, ISO 14000 e 14001, objetivando descartes ecologicamente corretos dos usuários de tecnologia de informação de forma que este possa contribuir de maneira simples para o meio ambiente. Através da coleta de dados relativos aos setores privados de tecnologia de informação e da investigação de informações, assim como a respeito da sustentabilidade pensada e realizada pelas empresas envolvidas, ocorre a troca de conhecimentos, podendo identificar os tipos de descartes adotados pelas empresas selecionadas, ao mesmo tempo em que gera conhecimento sobre os aspectos analisados, agregando valor ao tema proposto.

Este trabalho aborda os seguintes objetivos específicos: colaborar para esclarecer a utilização do uso da TI nas respectivas empresas, gerando informações; desenvolver uma pesquisa que propicie uma melhor forma de entendimento sobre TI Verde nas instituições privadas; reunir dados relevantes, coletados através de questionário aplicado na organização; apresentar a empresa a TI Verde e sua função favorável tanto para mesma quanto ao meio ambiente e o planeta; compreender e relatar as dificuldades exploradas durante a pesquisa.

Revbea, São Paulo, V. 11, № 4: 117-129, 2016. 
O tema apresenta significativa relevância à comunidade em questão, e com a parcela de participação se pode oferecer às empresas das cidades envolvidas um alerta e reflexão com os cuidados que se deve ter ao tratar os quesitos do e-lixo. Além de realizar um estudo com uma importância de abordagem em contexto real e local, agregar mais valor a comunidade empresarial de ambas cidades, economizar recursos ou reduzir gastos de energia, além realizar uma participação efetiva da comunidade empresarial, causando assim uma mudança de foco nos departamentos de $\mathrm{TI}$ das companhias, pois se tornar verde pode ter muitos significados para diferentes pessoas, mas nos dias atuais pensar verde é a chave do sucesso, tornando as empresas ecologicamente conscientes, através de uma economia sustentável.

\section{Tecnologia Verde: Algumas Abordagens e Definições}

Mais do que nunca, a informação e seus respectivos sistemas desempenham funções fundamentais nas organizações, representando-se como recurso estratégico para projetar e gerir organizações de forma competitiva e inteligente.

A sociedade da informação não é um modismo. Representa uma profunda mudança na organização da sociedade e da economia, havendo quem a considere um novo paradigma técnico-econômico (TAKAHASHI, 2000).

Para dar conotação estratégica à informação, a organização comumente passa por um ciclo evolutivo na forma de estágios, tais como: iniciação; contagio; controle; integração; administração de dados; e maturidade (REZENDE, 2008b).

A responsabilidade social, como é chamada com freqüência, implica um sentido de obrigação para a sociedade. Esta responsabilidade assume diversas formas, entre as quais se incluem proteção ambiental, projetos filantrópicos e educacionais, planejamento da comunidade, equidade nas oportunidades de emprego, serviços sociais em geral, de conformidade com o interesse público (DONAIRE, 1999).

O conceito de sustentabilidade mostrou-se até recentemente centrado em alguns temas, que obviamente tem relevância, mas faz parte de um contexto mais abrangente. Nas últimas décadas houve expressivo desenvolvimento das Tecnologias da Informação. O rápido desenvolvimento de equipamentos e consequente substituição dos obsoletos levaram o mercado à condição de grande gerador de resíduos tecnológicos e itens que contem altas taxas de componentes tóxicos (FERREIRA, 2010).

A economia ambiental de hoje, em outras palavras, tem que se libertar 0 quanto antes da economia ambiental de outros tempos (SILVERSTEIN, 1993).

Entre as diferentes variáveis que afetam o ambiente dos negócios, a preocupação ecológica da sociedade tem ganhado um destaque significativo em face de sua relevância para a qualidade de vida das populações (DONAIRE, 1999).

revista brasileira educação ambiental 
Informática ou Tecnologia da Informação (TI) pode ser conceituada como recursos tecnológicos e computacionais para guarda, geração e uso da informação e do conhecimento. Está fundamentada nos seguintes componentes: hardware e software e seus dispositivos e periféricos; software e seus recursos; sistemas de telecomunicações; gestão de dados e informações (REZENDE, 2008a).

Segundo Bezerra (2004), um sistema de computador é composto por duas partes, o hardware que é a parte física do computador e o software que é a parte lógica. Para Sommerville (2007) software é abstrato e intangível, não sendo somente um programa de computador, mas também toda a documentação e configurações de hardware necessárias para que ele funcione. Mattos (2005) afirma que hardware é a parte palpável do computador, citando como exemplos de hardware a impressora, as memórias, o monitor de vídeo, os cabos, a eletricidade entre outros.

O conceito de TI Verde consiste em dois principais blocos de construção - "verde" e "tecnologia da informação". Tecnologia da Informação refere-se a sistemas de informação baseados em computador, particularmente aplicações de software e hardware do computador. O "verde" em TI Verde refere-se à sustentabilidade ambiental aplicada na Tecnologia de Informação (SOBOTTA, 2010).

TI verde pode ser definida como um conjunto de práticas capazes de garantir que a atividade de uma empresa gere menor impacto ambiental. Com isso, é possível fazer com que a organização conquiste uma boa reputação sócio-ambiental (PINTO, 2011).

O setor de tecnologia da informação está relacionado dentro das organizações às atividades de inovação, segurança, suporte técnico, manutenção, implantação, serviços digitais e produtos, sendo um conjunto para geração, aplicação e uso da informação (REZENDE, 2008a).

As transformações verdes mais profundas e de maior valor agregado ainda enfrentam diversas resistências. Prédios ecologicamente sustentáveis, carros multicombustíveis, painéis solares, entre outros, ainda não é realidade para muitos negócios. A nova TI é uma exceção com bastante louvor neste campo da demanda com qualidade (MANSUR, 2011).

Sistemas de Informação é um conjunto organizado de pessoas, hardware, software, redes de comunicações e recursos de dados que coleta, transforma e dissemina informações em uma organização (O'BRIEN, 2004).

Segundo Boff (2012), desenvolvimento sustentável é aquele que atende as necessidades das gerações atuais sem comprometer a capacidade de gerações futuras de atenderem a suas aspirações.

As organizações interessadas em equacionar seu envolvimento com a questão ambiental necessitam incorporar em seu planejamento estratégico e operacional um adequado programa de gestão ambiental que possa 
compatibilizar os objetivos ambientais com os demais objetivos da organização (DONAIRE 1999).

Uma preocupação cada vez maior daqueles que lutam pelo bem da natureza é a respeito do lixo eletrônico. Apesar de cerca de $94 \%$ dos materiais contidos em aparelhos eletro-eletrônicos poderem ser reciclados, não é isso que acontece. Nestes produtos são encontradas diversas substâncias que podem causar sérios danos ao meio ambiente à saúde humana (CIRIACO, 2013).

O lixo eletrônico, computacional e/ou e-Lixo, muitas vezes é confundido com os spam que são recebidos nas caixas de e-mails, mas não é o tipo de lixo que estamos tratando, mas sim da parte física (hardware) onde ele é composto de plásticos e metais altamente tóxicos, então os computadores por sua vez vem a serem substituídos ou por obsolescência ou por se tornarem objetos que não estão em condições de uso ou de serem aproveitados, tornando-se resíduos eletrônicos (SILVA et al., 2009).

O lixo computacional é um dos principais problemas ambientais na atualidade, e seu descarte errado causa diversos danos ao planeta e a saúde, e através da compreensão obtida através do mapeamento dos conceitos e suas relações identificou-se também os motivos de se reciclar, fazer o reuso, o reaproveitamento e o seu tratamento (OLIVEIRA, 2010).

Define Pnuma (2011) economia verde como uma economia que resulta em melhoria do bem-estar da humanidade e igualdade social, ao mesmo tempo em que reduz significativamente riscos ambientais e escassez ecológica, e através disso o artigo mostra-se o quanto é importante tratar deste tema.

A Figura 1 mostra o mapa conceitual sobre o e-lixo, onde apresenta as razões pelas quais as empresas realizam o descarte do lixo eletrônico e os caminhos que estes resíduos podem percorrer. 


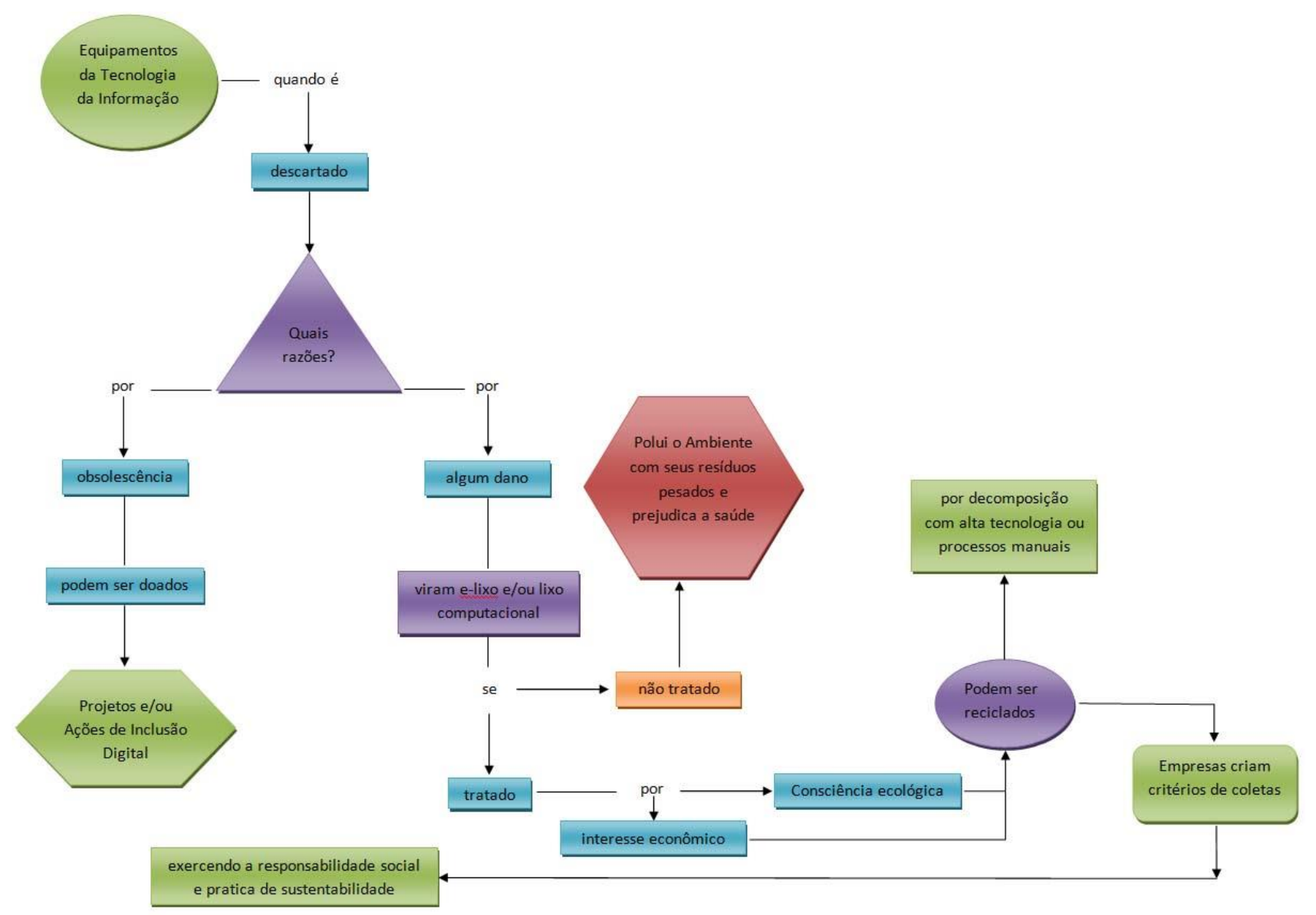

Figura 1: Mapa conceitual do lixo eletrônico.

Fonte: Adaptado de Calvão et. al. (2009).

\section{Material e Métodos}

A metodologia empregada compreende um estudo que possui caráter exploratório, descritivo, indutivo, com uma pesquisa a campo. Para delinear o problema, foram aplicados algumas técnicas e instrumentos na coleta e análise de dados, com a extração das informações das instituições privadas. Visando a descoberta de teorias e práticas que modificarão as existentes e estudos iniciais com finalidade de observar, registrar e analisar os fenômenos, identificando, fazendo análise de características, fatores e ou variáveis.

Trata-se de um trabalho com finalidade de averiguar um fenômeno dentro de um contexto local e real (entender como e por que as coisas funcionam), sendo que foram realizadas entrevistas com 69 empresas, de forma online e através de visitas a estas organizações localizadas nos municípios gaúchos de Quaraí e Sant'Ana do Livramento, estes que encontram-se localizados na faixa fronteira - Brasil - Uruguai aplicou-se um questionário com estrutura qualitativa, padronizada, estruturada com um roteiro previamente estabelecido fechado (ZAMBALDE; ALVEZ, 2008). 
Como forma de divulgar e socializar informações sobre a TI Verde e o elixo foi criada uma comunidade na rede social Facebook ${ }^{3}$, além desta ferramenta foi elaborado e implementado um web site para coleta de dados e informações, registrado no endereço eletrônico <www.tecnologiaverde.eco.br>, onde as empresas podiam preencher o questionário da pesquisa de forma online. Outras informações referentes ao tema também foram disponibilizados neste espaço, como notícias, curiosidades e dicas para o descarte correto dos equipamentos de tecnologia da informação.

Fazendo um chamamento para a problemática do lixo eletrônico, promovendo e incentivando a reciclagem do e-lixo e o reuso de equipamentos, aumentando seu tempo de vida e trabalhando para que não haja a contaminação do ambiente e da saúde por sua má disposição. A tabulação dos dados e a geração dos gráficos foram realizadas através do software Microsoft@ Office Excel.

Através de levantamento bibliográfico e revisão de literatura observaramse esses conceitos que seguem relacionados abaixo, com suas respectivas ações, algumas regulamentações existentes:

Selo Verde: é um selo aplicado a um produto certificando que o mesmo é menos prejudicial ao meio ambiente. A intenção, na concessão desse selo, é incentivar as empresas a fabricarem produtos com baixa quantidade de produtos tóxicos e com economia de energia (ORSA, 2009).

ISO: com o intuito de uniformizar as ações que deveriam ser tomadas nessa nova óptica para proteger o meio ambiente, a Organização Internacional para Normalização (ISO- Internacional Organization for Standardization) criou um sistema de normas que convencionou designar pelo código ISO 14000 (ISO, 2013).

ISO 14000 - é a uniformização das rotinas e dos procedimentos necessários para uma organização certificar-se ambientalmente, cumprindo um mesmo roteiro-padrão de exigências válido internacionalmente (ISO, 2013).

ISO 14001 - É uma especificação para um SGA (Sistema Gestão Ambiental) e foi desenvolvida para o uso na certificação por terceiras partes, embora possa ser também utilizada internamente para os fins de autodeclaração e como cláusula nos contratos da empresa (VALLE, 2002).

\section{Resultados e Discussão}

A pesquisa foi aplicada a 69 empresas das cidades de Sant'Ana do Livramento e Quaraí, ambas cidades fazem fronteira com o Uruguai. Em relação a quantidade de computadores, conforme apresenta a Figura 2 encontra-se assim configurada: $40 \%$ das organizações entrevistadas possuem até 5 computadores, $25 \%$ de 6 a 10 computadores, $14 \%$ de 11 a 20

\footnotetext{
${ }^{3}$ www.facebook.com/tcc.tec.verde
}

revista brasileira educação ambiental 
computadores, $5 \%$ de 21 a 30 computadores e $16 \%$ das empresas tem mais de 30 computadores.

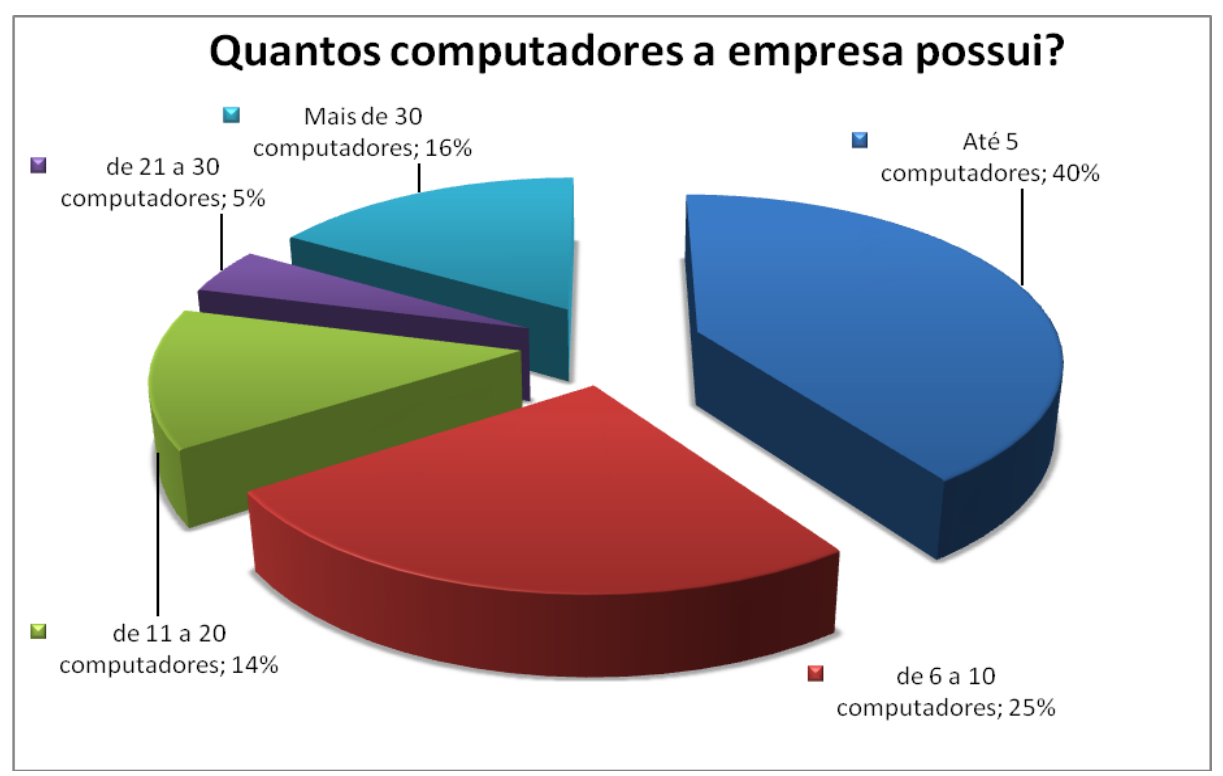

Figura 2: Gráfico resultante da quantidade de computadores que a empresa possui. Fonte: Elaborada pelos autores.

A maioria das empresas entrevistadas demonstra ter conhecimento sobre $\mathrm{TI}$ verde e suas praticas e assim responderam: Sim $57 \%$ e Não $43 \%$, como percebemos na Figura 3. Mas ao serem questionadas sobre a existência de projetos de TI Verdes na organização obteve-se 19\% Sim, 79\% Não e $2 \%$ em Branco, porém, ao serem indagadas se existe a possibilidade de aplicar/adotar projetos de TI Verde nas instituições, 91\% respondeu que Sim, $3 \%$ Não e $6 \%$ em Branco.

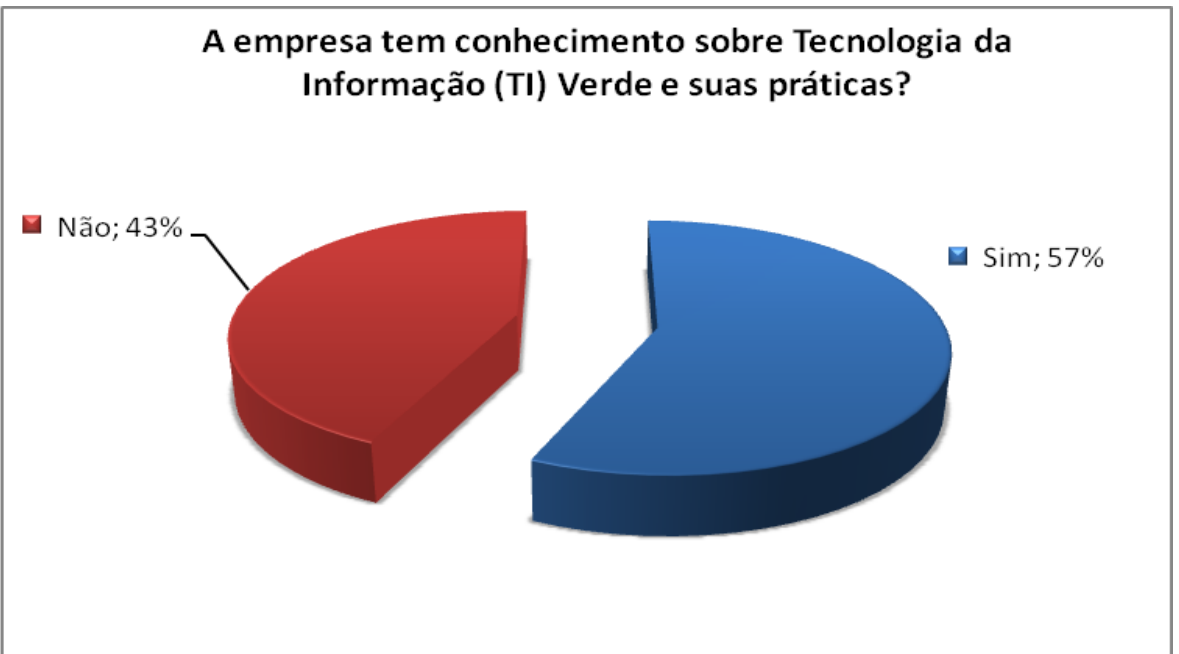

Figura 3: Gráfico informando a porcentagem sobre o conhecimento de TI Verde e suas práticas. Fonte: Elaborada pelos autores. 
Através da análise e a reflexão que foi gerada se observa que as corporações pesquisadas pensam de forma mais eficiente e sustentável com relação à utilização de seus recursos de $\mathrm{TI}$, trabalhando assim a gestão de sustentabilidade aplicada em TI Verde. Suas ações possibilitam alcançar um melhor desempenho no quesito de descarte de resíduos, significando proteger o ambiente e simultaneamente reduzir custos, certamente se pode dizer que essas preocupações e iniciativas merecem destaque, pois transmitem a consciência empresarial, ficando assim cada vez mais efetiva e tornando-se uma força impulsionadora que reflita o sucesso da mesma na sociedade.

Quando questionados sobre a existência de um espaço físico e específico para descarte de resíduos na empresa responderam: $54 \%$ Sim e 46\% Não. Como pode ser visualizada na Figura 4.

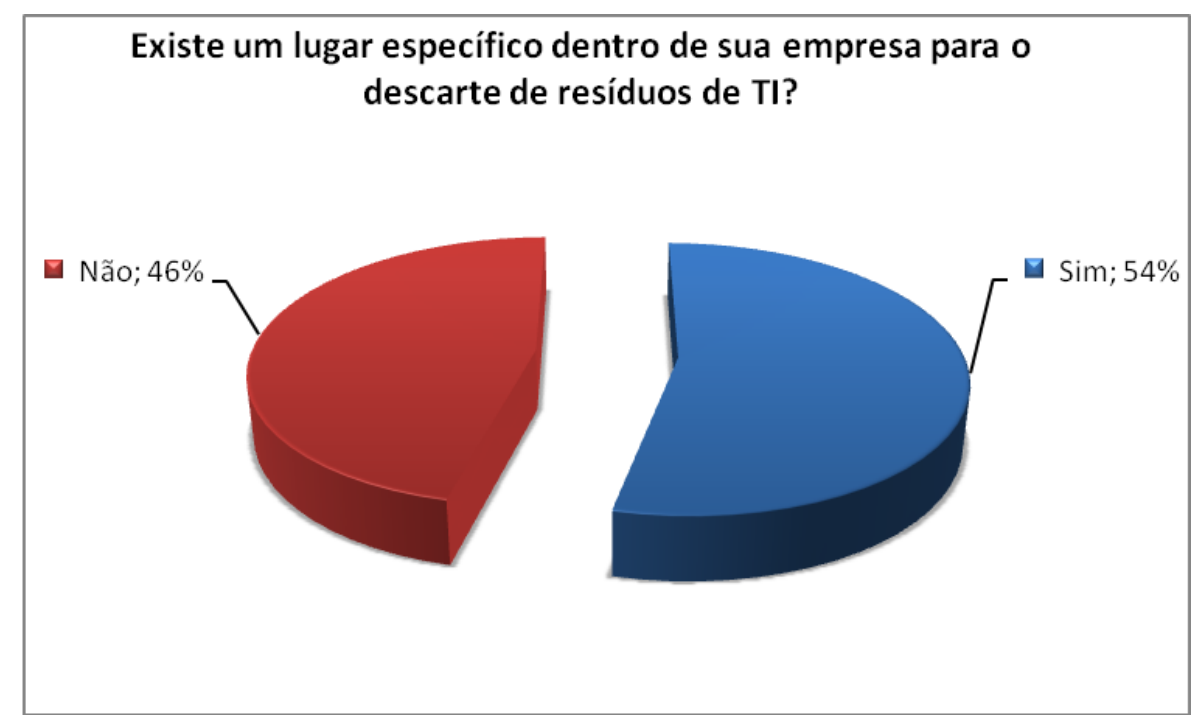

Figura 4: Gráfico informando a porcentagem sobre o local dentro da empresa para descarte dos resíduos de TI. Fonte: Elaborada pelos autores.

Verificando que a maioria das empresas não conta com um local apropriado dentro de seu espaço físico, então perguntamos como costumam realizar o descarte: $13 \%$ são jogados fora, junto com o lixo comum, $33 \%$ armazenados no depósito da empresa, $45 \%$ são encaminhados para locais específicos de reciclagem, 9\% utilizam outras formas de descarte. A Figura 5 apresenta a porcentagem de local de descarte realizado pelas organizações. Existe a preocupação de como é feito o descarte do e-lixo: $87 \%$ Sim e $13 \%$ Não, responderam a este questionamento. Com relação aos danos causados a saúde e meio ambiente $93 \%$ Sim e $7 \%$ Não. 


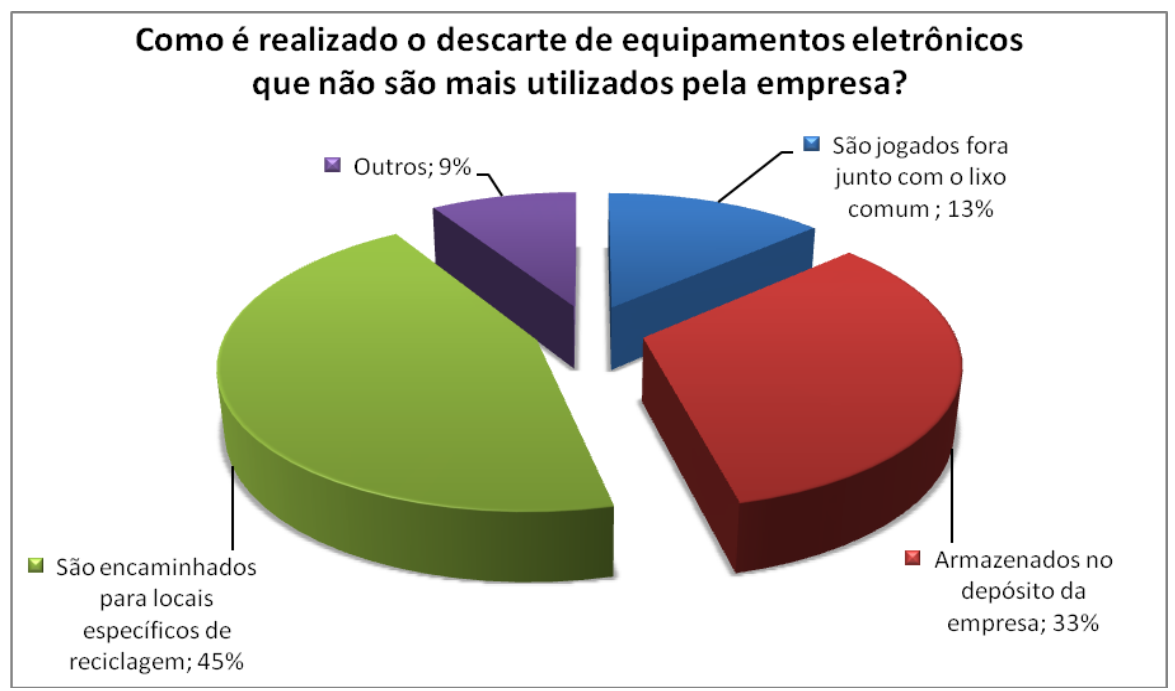

Figura 5: Gráfico mostrando como é feito o descarte do e-lixo na empresa. Fonte: Elaborada pelos autores.

Uma das alternativas encontradas pelas empresas como viável de uso da $\mathrm{Tl}$ de forma consciente é dar prioridade aos fornecedores que trabalhem com produtos sustentáveis, mesmo que o investimento financeiro no momento da aquisição seja maior: $46 \%$ Sim, 52\% Não e 2\% Branco. Veja o que demonstra a Figura 6.

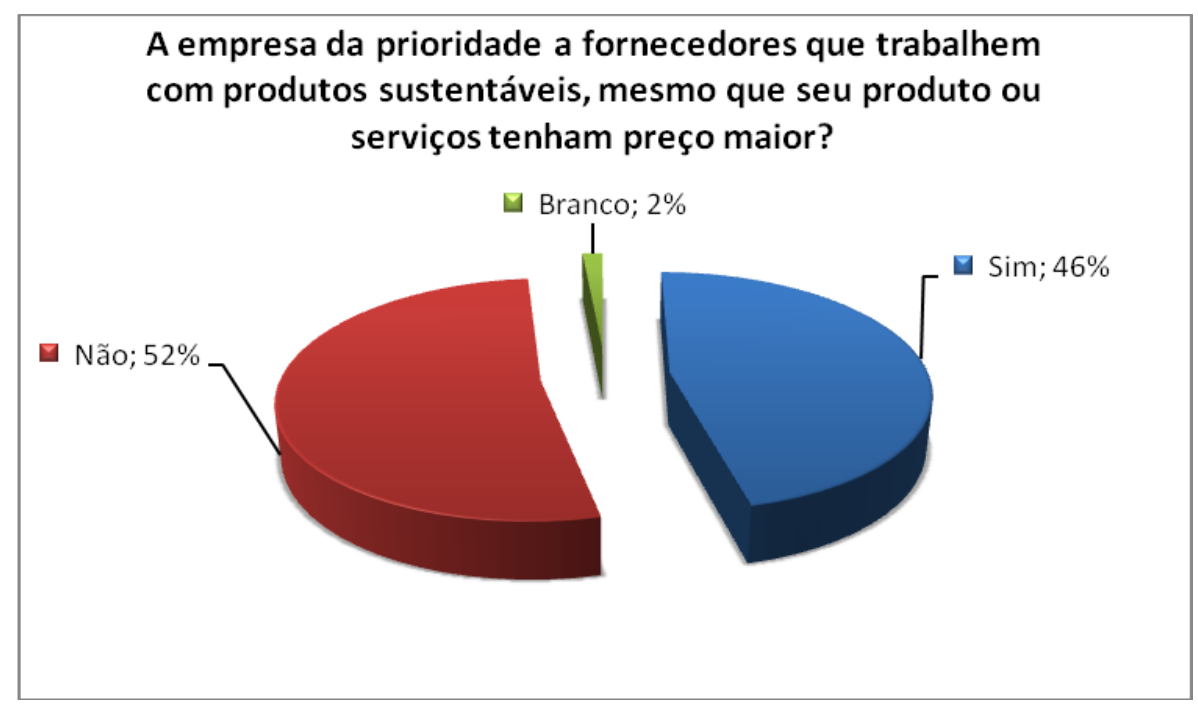

Figura 6: Gráfico que visualiza se fornecedores sustentáveis tem prioridade em suas compras no contexto da empresa. Fonte: Elaborada pelos autores.

Ao questionar sobre o que de fato conhecem da TI Verde, as empresas mostram que possuem conhecimento sobre as certificações como Selo Verde e ISO de sustentabilidade e assim responderam: $57 \%$ Sim, $42 \%$ Não e $1 \%$ Branco. Assim gerou a seguinte informação na Figura 7. Quando questionadas 
se sabem da existência de algum posto de coleta de e-lixo na cidade $43 \%$ afirmaram que Sim e outros $57 \%$ que Não.

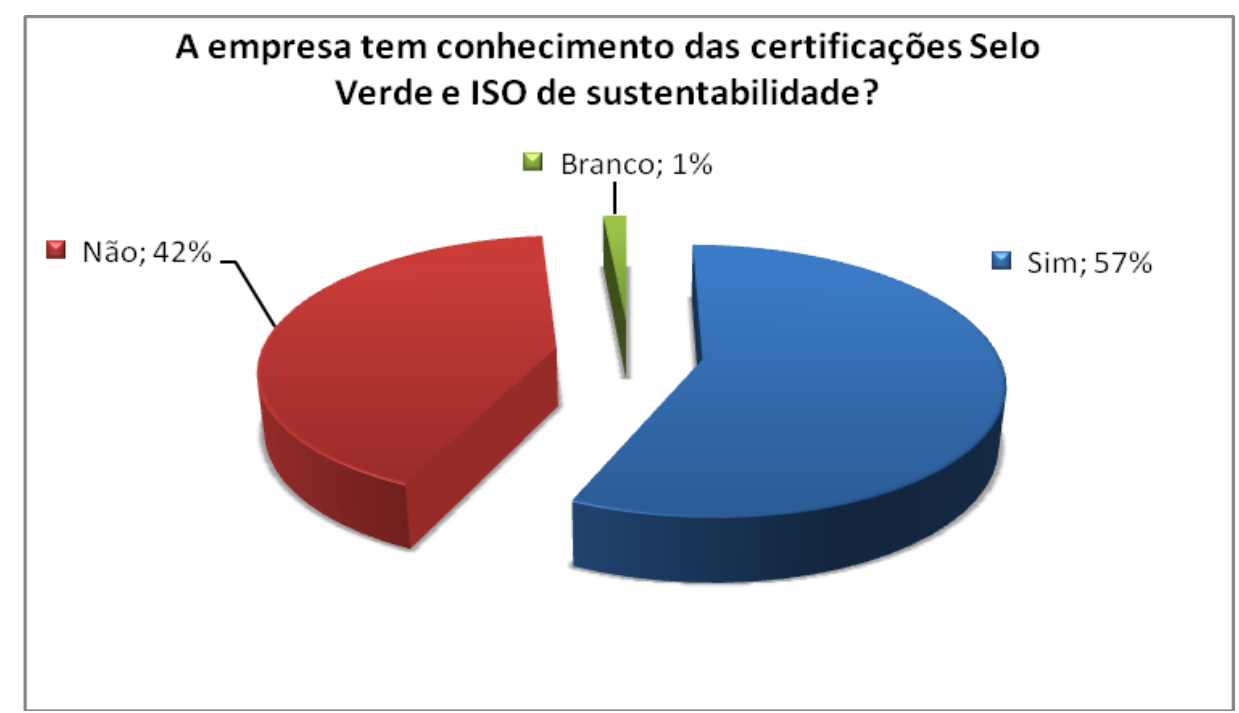

Figura 7: Gráfico que contempla o conhecimento da empresa com relação a alguma certificação verde. Fonte: Elaborada pelos autores.

Quanto a previsão feita para troca de equipamentos na empresa, verifica-se que: $8 \%$ o fazem de 1 a 2 anos, $34 \% 3$ a 4 anos, $22 \% 5$ a 10 anos, $2 \%$ mais de 10 anos e não há previsão de troca $34 \%$, como podemos ver na Figura 8. Na compra de equipamentos relacionados a $\mathrm{TI}$ foi questionado a respeito se há um planejamento para estas aquisições onde $49 \%$ responderam que $\operatorname{Sim}$ e $51 \%$ que Não, tendo em vista que as $46 \%$ das empresas pesquisadas possuem setor de $\mathrm{TI}$ e $54 \%$ Não possuem um setor específico.

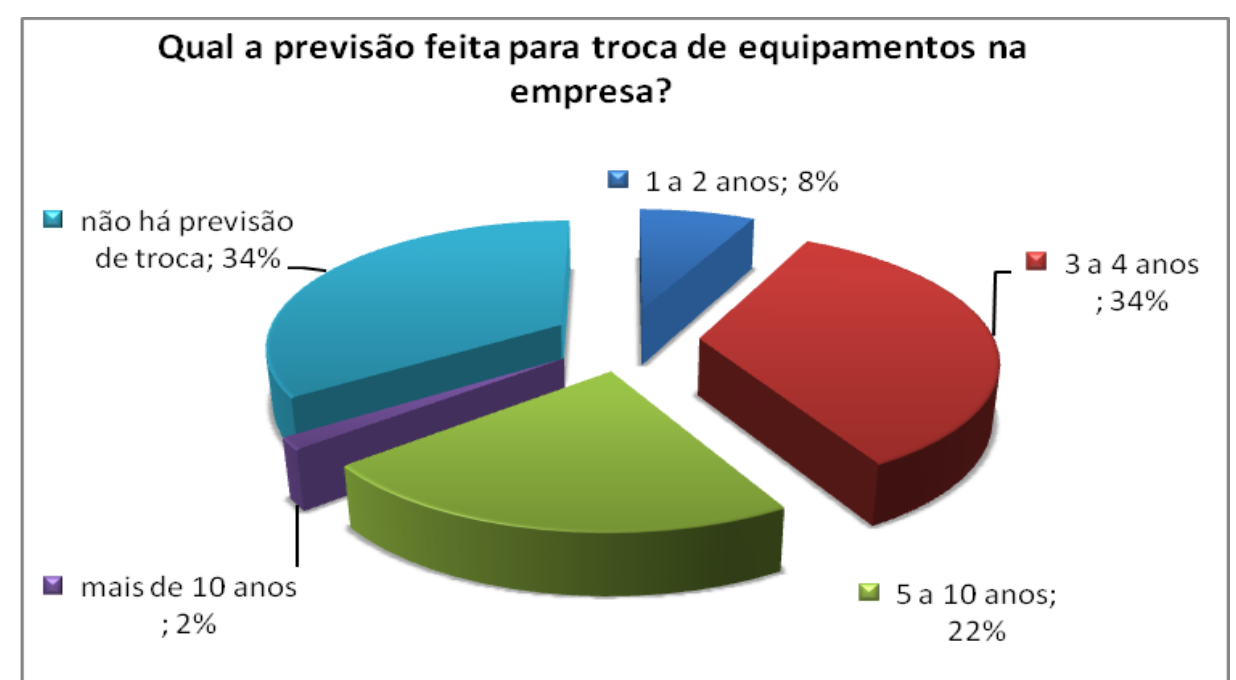

Figura 8: Gráfico contendo o tempo com que é feito a troca de equipamentos dentro da instituição. Fonte: Elaborada pelos autores. 


\section{Conclusões}

No universo pesquisado, apresenta-se uma boa proporção com relação a preocupação com o uso dos recursos oriundos da $\mathrm{Tl}$, sendo que um dos objetivos deste estudo foi mostrar a importância que deve se dar ao meio ambiente, e que através das organizações podem produzir formas de serem sustentáveis, onde percebe-se que as mesmas estão bastante empenhadas exercendo suas responsabilidades e suas participações com relação a redução do impacto da tecnologia no meio ambiente, mesmo que em estágio inicial.

Nas organizações de pequeno porte com até 10 computadores, apenas $15 \%$ delas tem projetos de TI Verde implantados, já as empresas que tem 11 ou mais computadores, esse percentual sobe para 33\%. Essa dificuldade das pequenas empresas em implantar projetos de TI Verde se deve a questão de conhecimento na área ou por questões financeiras.

A amostra escolhida permitiu observar um contexto real e local, sendo realizada por conveniência e acessibilidade, o número reduzido desta amostra leva a considerar os resultados encontrados apenas para a população em questão, podendo não representar a realidade em outra região, este estudo apesar de apresentar limitações pode colaborar para futuras pesquisas a respeito da TI Verde.

\section{Referências}

ABREU, A.F; MONTEIRO, M.S.; ROMITO, P.R. Ti Verde - Implementação de Práticas Sustentáveis em Empresa de Tecnologia da Informação. Resende: Anais do IX Simpósio de Excelência em Gestão e Tecnologia, 2012.

BEZERRA, I.D. Hardware sem mistérios. Terra, 2004.

BOFF, Leonardo. Sustentabilidade: o que é, o que não é. Petrópolis, Rio de Janeiro: Vozes, 2012. 200p.

CALVÃO, A.M.; ROSE D.E.; RIBEIRO, D.S.; D' ALMEIDA, M.H.B.; ALMEIDA, R.L.; LIMA, R.L. O Lixo Computacional na Sociedade Contemporânea. Cascavel: Anais do I ENINED - Encontro Nacional de Informática e Educação, 2009.

CIRIACO, D. Tecnologia Verde. Disponível em: $<$ http://www.tecmundo.com.br/1588-tecnologia-verde.htm>. Acesso em 22 mai. 2013.

DONAIRE, D. Gestão ambiental de empresas. 2. ed. São Paulo: Atlas, 1999. 169p.

FERREIRA et al. TI Verde: Tecnologias conectadas com a Sustentabilidade Ambiental. Revista Eletrônica Mestrado Educação Ambiental. ISSN 15171256, v.24, p.253,Jan./Jul. 2010.

ISO, International Organization for Standardization. ISO 14000 Environmental managemnet. $<$ http://www.iso.org/iso/iso14000 > Acesso em 15 abr. 2013. Disponível em 
MANSUR, R. Governança de TI Verde: Ouro Verde Da Nova TI. Rio de Janeiro: Editora Ciência Moderna, 2011. 211p.

MATTOS, A.C.M. Sistemas de informação: uma visão executiva. Saraiva, 2005.

NANNI, H.C.; PASSOS, A.G. Ti Verde: Práticas Sustentáveis para o Descarte de Equipamentos Eletrônicos. Revista Científica Integrada. ISSN 2359-4632 v.1, n.3, 2014.

O'BRIEN, J.A. Sistemas de informação e as decisões gerenciais na era da internet. 2.ed. São Paulo: Saraiva, 2004. 431p.

OLIVEIRA, R.S. et al. O Lixo Eletroeletrônico. Química Nova na Escola, v. 32, n.4, p 240 - 248, nov 2010.

ORSA et al. Selo Verde Cultura Digital Profissional: Cartilha informativa para reconhecimento em Cultura Digital responsável. Disponível em: $<$ http://www.seloverde.org.br/> p 01 - 31. Acesso em 19 ago. 2013.

PINTO, T.M.C; SAVOINE, M.M. Estudo sobre TI Verde e sua aplicabilidade em Araguaína. Revista Cientifica do ITPAC, Araguaína, TO, v 4. n 2,p 01-15, abr. 2011.

PNUMA. Programa das Nações Unidas para o Meio Ambiente. Rumo a uma Economia Verde. Caminhos para o Desenvolvimento Sustentável e a Erradicação da Pobreza: Síntese para Tomadores de Decisão, 2011. 52p.

REZENDE, D.A. Planejamento de Sistemas de Informação e Informática: guia prático para planejar a tecnologia da informação integrada ao planejamento estratégico das organizações. 3.ed. São Paulo: Atlas, 2008a. $167 p$.

REZENDE, D.A. Sistemas de Informações Organizacionais: guia prático para projetos em cursos de administração, contabilidade e informática. 3. ed. São Paulo: Atlas, 2008b. 133p.

SILVA, L.A.M.; FRAGA, V.; ARAÚJO, Y.D.V. Lixo eletrônico. Guarujá: Anais do Simpósio Internacional de Ciências Integradas da UNAERP, 2009.

SILVERSTEIN, M. A Revolução Ambiental. Rio de Janeiro: Editora Nórdica, 1993. 199p.

SOBOTTA, A.T. et al. Greening IT: How Greener IT Can Form a Solid Base For a Low-Carbon Society, ISBN: 978-87-91936-02-9, 1. ed. Mai, Creative Commons, 2010. 272p.

SOMMERVILLE, I. Engenharia de software. 8a Edição, Pearson Prentice Hall, 2007.

TAKAHASHI, T. Sociedade da Informação no Brasil: Livro Verde.Brasília. Ministério da Ciência e Tecnologia, 2000. 195p.

VALLE, C.E. Qualidade ambiental: ISO 14000. 4. ed. São Paulo: Senac São Paulo, 2002. 193p.

ZAMBALDE, A.L.; ALVES, R.M. Monografia ou Trabalho de Conclusão de Curso. Lavras. Editora UFLA, 2008. 90p. 